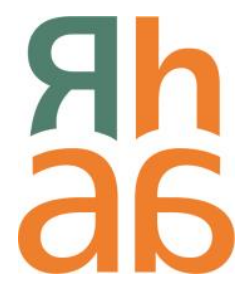

\title{
Seguridad, migración, trata de personas y tráfico de migrantes en Chile (2010-2018)
}

\section{Security, migration, trafficking in persons and migrant smuggling in Chile: 2010-2018}

\author{
Guillermo Bravo Acevedo \\ Academia Nacional de Estudios Políticos y Estratégicos \\ Santiago, Chile \\ gbravo@anepe.cl
}

\begin{abstract}
Resumen
En el siglo XXI, los movimientos de población forman parte de la globalización y la economía mundial. De esta manera, las migraciones internacionales y regionales han provocado cambios en las políticas migratorias de muchos países, pero, al mismo tiempo, han abierto espacios para que el crimen organizado transnacional desarrolle rentables negocios ilícitos, que se relacionan con el tráfico de migrantes y la trata de personas. Chile no escapa a esta situación ya que el crecimiento económico ha convertido al país en una sociedad receptora atractiva para migrantes regulares transfronterizos y regionales y, también, para que el crimen organizado desarrolle su negocio de la trata de personas y el tráfico de migrantes.
\end{abstract}

Palabras clave: migración; seguridad; trata de personas; tráfico de migrantes.

\section{Abstract}

Since man inhabits the earth there have been population movements. In the twentyfirst century, such movements are part of globalization and the world economy. In this way, international and regional migrations have caused changes in the migration policies of many countries, but, at the same time, they have opened spaces for

Cómo citar este artículo/ How to cite this article: Bravo Acevedo, G. (2021). Seguridad, migración, trata de personas y tráfico de migrantes en Chile: 2010-2018. Revista de Historia Americana y Argentina, 56 (2), pp. 209-231. https://doi.org/10.48162/rev.44.017 
transnational organized crime to develop profitable illicit businesses, which are related to the smuggling of migrants and human trafficking. Chile does not escape this situation since economic growth has made the country an attractive receiving society for regular cross-border and regional migrants and, also, for organized crime to develop its business of human trafficking and migrant smuggling.

Key words: migration; security; human trafficking; migrant smuggling

Recibido: 30/03/2021. Aceptado: 29/06/2021

\section{Introducción}

La historia del hombre, desde los primeros tiempos hasta el siglo $\mathrm{XX}$, ha registrado múltiples movimientos de población en busca de mejores condiciones de vida y bienestar social y económico. En el siglo XXI, los flujos migratorios internacionales forman parte de la estructura de la globalización y conforman un factor importante de la mundialización de la economía.

Sin embargo, este escenario globalizado, junto con la migración internacional y regional, han provocado importantes cambios en las políticas migratorias de los países. Además, han facilitado que el crimen organizado transnacional pueda desarrollar diversos negocios ilícitos, especialmente los relacionados con el tráfico de migrantes y la trata de personas que han complicado aspectos interconectados con la seguridad.

En el caso particular de Chile, el crecimiento económico, la facilidad para la entrada y el cruce de fronteras han convertido al país en un destino atractivo para los inmigrantes transfronterizos y regionales en los últimos años, y han convertido al país en sociedad receptora. Esta situación ha facilitado la migración irregular junto al tráfico de migrantes y la trata de personas.

\section{Movimientos migratorios, globalización y seguridad}

La globalización, la mundialización económica y, los masivos movimientos de población a comienzos del siglo XXI, han generado cambios significativos en el orden internacional, tanto en las áreas económicas, sociales, políticas y, de las relaciones internacionales debido a que el 
espacio transnacional se constituyó en el marco de la globalización provocando diversos cambios. Por un lado, se liberalizaron flujos de capital, mercancías, tecnología e información y, por otro, se reforzaron los controles fronterizos y aumentaron las dificultades impuestas a la circulación de las personas y de la fuerza de trabajo debido a que estos procesos representan la fase activa de la evolución del capitalismo (véase a Beck, 1998; Castells, 2005; Dehesa, 2000; Zolo, 2000; Trigo Portela, Tremosa I Balcells y Viñeta, 2003).

Por otra parte, un cambio importante se presentó con los movimientos de población. A diferencia de lo sucedido con los flujos migratorios del siglo XX, en los que la mayoría de los migrantes eran europeos que venían hacia América, las oleadas migratorias de finales del siglo $X X$ y comienzos del $\mathrm{XXI}$, se desplazaron hacia el norte, a países desarrollados, y convirtieron la migración en una "estrategia de subsistencia generalizada" (Itzingsohn, 2003, p. 77).

Como consecuencia del proceso globalizador otro cambio significativo, pero de carácter negativo, que ha impactado tanto a la sociedad internacional en su conjunto como a los países en forma particular, ha sido "(...) la transformación de la criminalidad, [que] pasó de estar circunscrita a las fronteras de un país a expandir sus actividades delictivas de una manera espectacular, aumentando sus beneficios así como también el número de víctimas" (Della Penna, 2014, p. 47).

Este conjunto de cambios se sumó a los conflictos tradicionales del escenario mundial, razón por la que la OEA (2003) calificó estos nuevos problemas, en su reunión de México de 2003, como "amenazas multidimensionales", porque su carácter invasivo involucraba varios aspectos simultáneamente. Entre las amenazas que la OEA menciona figuran, entre otras, "el terrorismo, la delincuencia organizada transnacional, el problema mundial de las drogas, la corrupción, el lavado de activos, el tráfico ilícito de armas y las conexiones entre ellos; la trata de personas; los ataques a la seguridad cibernética (...)" (OEA, 2003, p. 4)

A su vez, los movimientos migratorios internacionales, regionales y transfronterizos han asumido el carácter de estrategia de subsistencia económica y de movilidad social se fueron conformando rápidamente como un fenómeno global, complejo e integral. Global, por su extensión planetaria y por tanto es imposible examinarlos desde una perspectiva estrictamente 
nacional o local. Complejo, debido a lo heterogéneo y plural, pues son diversos en sus orígenes e integración en la sociedad receptora. Integral, por su dimensión social que involucra diferentes aspectos, tanto laborales y económicos, como culturales, jurídicos y políticos (Lucas de, 2004, pp. 198199). Este proceso demuestra otra seña que asocia actualmente la globalización económica y los movimientos de población con el campo de la seguridad.

Estas nuevas condiciones han fomentado la migración irregular e indocumentada; calificativo que ha servido de argumento para construir un discurso que considera a las migraciones como un riesgo, una amenaza a la seguridad. En otras palabras, este tipo de migraciones podrían calificarse como "amenazas multidimensionales" por dos razones principales; una, porque en la actualidad la libertad de movimiento de las personas es difícil de controlar y, dos, porque la trata de personas y el tráfico de migrantes están controlados por la economía criminal y corresponden a flujos migratorios que debido a su clandestinidad y permanente movilidad no es posible fiscalizarlos debidamente por los servicios de seguridad de los países, tanto en el plano nacional como internacional

Pese a estos problemas, los movimientos migratorios concitan la atención por igual de los países emisores y receptores aunque el tipo de preocupación sea distinto para cada uno de ellos.

Mientras los países emisores tienen en cuenta los riesgos y las consecuencias de este tipo de migración para sus nacionales, las sociedades receptoras se empeñan en regularizar a los que ya están dentro o de impedir que entren los que lo intentan (Bravo, 2015, p. 148).

Frente a esta disyuntiva, los gobiernos tratan de establecer políticas públicas migratorias que sean capaces de distinguir entre la migración legal de la ilegal, porque es necesario calificar a dichas migraciones como regulares o irregulares (Organización Internacional para las Migraciones. (OIM, 2006). La razón fundamental de esta distinción es que "(...) la migración irregular es la que causa una mayor preocupación a los gobiernos de los países receptores de migrantes porque es la que regularmente se asocia a problemas y riesgos de seguridad" (Bravo, 2015, p. 145). 
En cuanto a la magnitud de la migración internacional, las estadísticas de las Naciones Unidas, señalan que la migración internacional en 2017 alcanzó la cifra de 645.593 .000 migrantes, es decir, el 8,6\% respecto de una población mundial estimada en 7.550.262.000 personas. Los migrantes de origen latinoamericano alcanzaban a 37.720 .000 de personas, con un $14.6 \%$ sobre el total mundial (United Nations (UN), 2017, p. 9). Las sociedades receptoras de "(...) los países o zonas que experimentaron las tasas de crecimiento más rápidas durante este periodo fueron Angola, Qatar y Chile" (UN, 2017, p. 7). En cuanto a la migración regional, es decir, en América Latina y el Caribe, los datos estadísticos demuestran que, entre 2000 y 2017, hubo un crecimiento del $52 \%$, pasando de 24.800 .000 personas en el año 2000 a 37.720.000, en 2017 (UN, 2017, p. 10).

Como se ha indicado, Chile se convirtió en un país más atractivo para la migración internacional y regional porque los índices de desarrollo económico que se alcanzaron en los últimos años equilibraron el crecimiento y desarrollo. Un informe de OCDE expresa: "La creciente fortaleza económica de Chile y el deterioro de la situación en otros países latinoamericanos han hecho del país una alternativa atractiva para los migrantes regionales" (Naciones Unidas (NU), 2012).

De esta manera, en las dos primeras décadas del siglo XXI la sociedad chilena recibió un número importante de migrantes, cuyo perfil respondía a una nueva realidad debido a que el país se había convertido en "(...) una sociedad receptora estable en lo político, acogedora en lo social y atractiva en lo económico (Bravo y Norambuena, 2018, p. 85).

El primer cambio observado en el flujo migratorio estuvo determinado por los tres rasgos señalados, Así, los migrantes que comenzaron a llegar al país, desde 1982, pasaron del perfil europeo al latinoamericano; cambio que se refleja en las estadísticas de 1982 y 2012: En el censo de 1982 se contabilizó un porcentaje de $31.8 \%$ de europeos y $54.5 \%$ de americanos; $y$, en el censo de 2012 los porcentajes fueron de $10.5 \%$ y $80.6 \%$ para los mismos indicadores, respectivamente (Instituto Nacional de Estadísticas (INE), 1982-2012). 
El constante flujo de migrantes que llegaba al país presentó una nueva imagen de ese movimiento de población, y configuró en los primeros años del siglo XXI la figura de la denominada Nueva Migración. Sus rasgos específicos fueron:

(...) preferentemente latinoamericano, más del $80 \%$ son de América Latina, en cuanto a su región de origen; con relación al género, el $52.9 \%$ de los migrantes son mujeres; se trata de una población joven, cuyo promedio de edad está por sobre 32 años, lo cual la califica como población activa, que está en condiciones de posicionarse en el mercado de trabajo nacional (Bravo y Norambuena, 2018, p. 99).

En suma, los migrantes de la Nueva Migración que llegan a Chile podrían constituirse en un riesgo económico para el mercado de trabajo interno y no necesariamente un riesgo para la seguridad nacional y la estabilidad democrática. A menos que sean promovidos o financiados por redes de trata de personas, de prostitución, de tráfico de personas, o sean activos participantes del tráfico de drogas o pertenezcan a las filas del crimen organizado transnacional.

\section{Trata de personas, tráfico de migrantes}

En lo que va corrido del siglo XXI los movimientos migratorios se incorporaron a la globalización como uno de sus componentes principales, toda vez que el libre comercio y la libre circulación de capitales, han permitido una mayor movilidad de personas transformando el carácter y perfil de los migrantes.

La migración, la trata de personas y el tráfico de migrantes son conceptualmente diferentes, pero también es cierto que se relacionan entre sí. Si se considera el término migración de acuerdo con la Organización Internacional para las Migraciones (OIM), se define como "movimiento de población hacia el territorio de otro Estado o dentro del mismo que abarca todo movimiento de personas sea cual fuere su tamaño, su composición o sus causas; incluye migración de refugiados, personas desplazadas, personas desarraigadas, migrantes económicos" (OIM, 2006, p. 38). Desde luego, este concepto es polisémico pues incluye toda clase de movimiento de personas y, dentro de esos movimientos están la trata de personas y el tráfico de migrantes. 
Sin embargo, la decisión de migrar de un individuo, o de un grupo de ellos, muchas veces surge de la necesidad de buscar nuevos horizontes, aunque la decisión estè acompañada de factores sociales y culturales que no necesariamente responden a una lógica económica racional. En otras ocasiones, frente a un conflicto, una crisis económica o un desastre ambiental, las personas se ven obligadas a migrar como medio de subsistencia, lo que tipifica otra forma de migración. En el primer caso, la decisión libre y espontánea de emigrar caracteriza a la migración regular y documentada, en tanto en el segundo la fórmula utilizada es la migración irregular, indocumentada, situación que es aprovechada por organizaciones delictuales.

Entonces, es necesario establecer diferencias generales entre los conceptos de trata de personas y tráfico de migrantes. La trata de personas se refiere a un negocio que realiza un sujeto que ofrece falsas promesas de trabajo a personas que migran hacia otro país o incluso dentro del mismo, bajo ciertas condiciones que no implican consentimiento efectivo, pero que luego se transforman en amenazas y obligaciones de las que no pueden evadirse. En cambio, el tráfico ilícito de migrantes se posibilita cuando un traficante, por medio de un elevado pago, posibilitará la entrada ilegal al migrante a un país receptor. Posiblemente, cuando el individuo llegue al país de destino rompa los lazos de contacto con el traficante.

Para estos dos delitos es difícil contar con datos estadísticos sobre la cantidad de personas que cruzan las fronteras de cualquier país del mundo, tanto con el método de la trata de personas como por medio del tráfico de migrantes. No cabe duda que los operadores que manejan estos negocios y son responsables de estos crímenes pertenecen al crimen organizado transnacional. La razón fundamental de esta falta de datos seguros se debe a que son actividades delictuales silenciosas, casi invisibles, que forman parte de una economía informal muy rentable.

\section{¿Qué es la trata de personas?}

La trata de personas es una migración totalmente distinta puesto que las personas son trasladadas de un país a otro, y a veces dentro del mismo territorio, por un traficante cuyo fin es explotar su trabajo o servicios. Las Naciones Unidas, en la Convención de Palermo (2000), definió la trata de personas como: 
La captación, el transporte, el traslado, la acogida o la recepción de personas, recurriendo a la amenaza $o$ al uso de la fuerza $u$ otras formas de coacción, al rapto, al fraude, al engaño, al abuso de poder o de una situación de vulnerabilidad o a la concesión o recepción de pagos o beneficios para obtener el consentimiento de una persona que tenga autoridad sobre otra, con fines de explotación. Esa explotación incluirá, como mínimo, la explotación de la prostitución ajena u otras formas de explotación sexual, los trabajos o servicios forzados, la esclavitud o las prácticas análogas a la esclavitud, la servidumbre o extracción de órganos (ONU.UNODOC, 2004, pp. 4445).

De la anterior definición es posible inferir que la trata de personas se diferencia del tráfico de migrantes en los siguientes aspectos (Tabla 1):

Tabla 1. Diferencias entre Trata de personas y Tráfico de Migrantes

\begin{tabular}{|c|l|l|}
\hline Ítems & \multicolumn{1}{|c|}{ Trata de personas } & Tráfico de migrantes \\
\hline Consentimiento & $\begin{array}{l}\text { No implica consentimiento } \\
\text { para explotación o el } \\
\text { consentimiento se } \\
\text { encuentra viciado. }\end{array}$ & $\begin{array}{l}\text { Implica una operación } \\
\text { comercial voluntaria } \\
\text { por medio de un } \\
\text { contrato verbal }\end{array}$ \\
\hline $\begin{array}{c}\text { Deransgredidos } \\
\text { Transnacionalidad }\end{array}$ & $\begin{array}{l}\text { Delito contra las personas } \\
\text { Delito contra los derechos } \\
\text { humanos }\end{array}$ & $\begin{array}{l}\text { Delito contra el } \\
\text { Estado. } \\
\text { Se violan las leyes } \\
\text { nacionales }\end{array}$ \\
\hline & $\begin{array}{l}\text { Las personas se movilizan } \\
\text { tanto dentro como fuera del } \\
\text { país. No siempre cruzan } \\
\text { fronteras de manera ilegal }\end{array}$ & $\begin{array}{l}\text { Las personas cruzan } \\
\text { las fronteras en forma } \\
\text { ilícita en condiciones } \\
\text { peligrosas o } \\
\text { degradantes }\end{array}$ \\
\hline Explotación & $\begin{array}{l}\text { Implica la explotación } \\
\text { persistente de las víctimas } \\
\text { de alguna manera para } \\
\text { generar ganancias ilegales } \\
\text { para los traficantes }\end{array}$ & $\begin{array}{l}\text { El tráfico ilícito termina } \\
\text { con la llegada de los } \\
\text { migrantes a su } \\
\text { destino }\end{array}$ \\
\hline
\end{tabular}

A pesar de las diferencias señaladas, estos delitos forman parte de los negocios ilegales del crimen organizado transnacional (COT). En efecto, el informe de Global Financial Integrity, Transnational Crime and the 
Developing World, de marzo 2017 establece que “(...) el negocio de la delincuencia transnacional a nivel mundial está valorado en un promedio de 1,6 billones de dólares a 2,2 billones de dólares anuales" (Channing, 2017). El escrito detalla, además, las ganancias de 11 actividades criminales con las cuales cubren los siguientes mercados, según se puede observar en la Tabla 2.

Tabla 2. Mercados y actividades del crimen organizado transnacional

\begin{tabular}{|c|c|}
\hline Crimen Transnacional & Valor Estimado Anual (US\$) \\
\hline Falsificación & 923 mil millones a 1,13 billones \\
\hline Narcotráfico & 426 mil millones a 652 mil millones \\
\hline Registro ilegal & 52 mil millones a 157 mil millones \\
\hline Trata de personas & $\mathbf{1 5 0 . 2}$ mil millones \\
\hline Minería ilegal & 12 mil millones a 48 mil millones \\
\hline Pesca INDNR ${ }^{\star}$ & 15.5 mil millones a 36.4 mil millones \\
\hline Comercio ilegal de vida silvestre & 5 mil millones a 23 mil millones \\
\hline Robo de petróleo crudo & 5.200 millones a 11.9 mil millones \\
\hline Tráfico de armas pequeñas y ligeras & 1.700 millones a 3.500 millones \\
\hline Tráfico de órganos & 840 millones a 1.700 millones \\
\hline Total: & 1.6 trillones a 2.2 trillones \\
\hline
\end{tabular}

*Pesca ilegal, no declarada y no reglamentada

Fuente: Global Financial Integrity.Transnational Crime and the Developing World, 2017.

Se infiere de la tabla precedente que la trata de personas es un delito con una alta rentabilidad que ocupa el tercer lugar en los negocios ilegales del COT (Código de Operación de Traslado). Además, de ser muy lucrativo, tiene un bajo riesgo criminal debido a la invisibilidad del delito y a la escasa denuncia que realizan las víctimas por temor a represalias.

El desconocimiento del delito, el temor a entregar la información, la estigmatización y "naturalización" que lo invisibilidad, los subterfugios y diversas formas de ocultamiento de las personas menores de edad, 
entre otros, se transformaron en serios obstaculizadores para la detección de casos de niños/as y adolescentes víctimas de trata de personas. (Araya Castelli, et al, 2007, p. 29).

Sin embargo, el delito está presente en todos los países del mundo y afecta principalmente a mujeres, a tal punto que la UNODOC declara que

Dos terceras partes de las víctimas de la trata de personas de todo el mundo son mujeres. La gran mayoría de ellas son jóvenes que han sido engañadas con falsas promesas de empleo y después violadas, drogadas, encerradas, golpeadas 0 amenazadas con actos de violencia, o a las que se han impuesto deudas, se ha despojado de su pasaporte o se ha chantajeado (ONU. UNODOC, s/f).

Chile no escapa a este problema mundial sobre la trata de personas. El Trafficking in Persons Report 2018 (Informe sobre la trata de personas 2018), elaborado por el Departamento de Estado de Estados Unidos, en marzo 2019, describe el perfil del tráfico y señala que Chile es un país de origen, tránsito y destino para hombres, mujeres y niños sometidos a trata sexual y trabajo forzoso (Departamento de Estado de Estados Unidos, (DEEU), 2018, pp.137-138). También, reafirma que las víctimas objeto de trata son requeridas para trabajar en industrias como la construcción, minería, agricultura y servicios domésticos, según lo ya señalado en el reporte de 2016 (DEEU, 2016, pp. 128-129). Esta afirmación concuerda con los datos entregados por la Mesa Intersectorial Trata de Personas, del Ministerio del Interior de Chile, que menciona a Argentina, República Dominicana, Bolivia, Perú, Paraguay, Colombia y Ecuador como los principales países de origen de los 267 migrantes identificados como víctimas de esta actividad criminal, como se observa en la Tabla 3 (Ministerio del Interior, (Ministerio del Interior -MIN-, 2019).

Desde la promulgación de la Ley $\mathrm{N}^{\circ} 20.507$, el 8 de abril de 2011 (MIN, 2019 , p. 3), el gobierno de Chile cumple las normas para la eliminación del tráfico de la trata y, según el informe del Departamento de Estado, demostró esfuerzos serios y sostenidos durante el período que abarca el informe. El reporte señala que los traficantes, al tanto de la ley sobre trata de personas promulgada en 2011, “(...) están cambiando sus operaciones, incluyendo el evitar la participación directa en actividades ilegales, la creación de contratos de trabajo a las víctimas a través de terceros, y el establecimiento de empresas ficticias para justificar las ganancias ilícitas" (DEEU, 2018, p. 137) (tabla 3). 
Tabla 3. Trata de Personas en Chile por Nacionalidad. 2011 - 2019

\begin{tabular}{|c|c|}
\hline Nacionalidad & № de Migrantes \\
\hline Boliviana & 80 \\
\hline Paraguaya & 68 \\
\hline Colombiana & 40 \\
\hline Ecuatoriana & 14 \\
\hline Argentina & 14 \\
\hline Dominicana & 10 \\
\hline Peruana & 10 \\
\hline Total & 236 \\
\hline
\end{tabular}

Fuente: Elaboración propia con datos de Mesa Intersectorial Trata de Personas, 2019 p. 12.

Por lo mismo, entre 2011 y 2013 Chile se mantuvo en el Nivel 2 [TIER 2], pero a partir del año 2014 hasta 2019, pasó al Nivel 1 [TIER 1]. Esta posición se avala por los esfuerzos para triplicar el número de condenas, por el aumento del financiamiento de los servicios de víctimas de la trata sexual infantil y por un presupuesto gubernamental de acción nacional.

La posición de Chile en el ranking TIER se refleja en las estadísticas publicadas por la Mesa Intersectorial Trata de Personas en 2019, con datos desde 2011 a 2019. La Tabla 4 contiene las causas seguidas por la autoridad de justicia y revela la cantidad de 267 víctimas totales por el delito de trata de personas.

La Tabla 5 presenta información sobre las Víctimas de trata de personas por año y tipo, y la Tabla 6, los Condenados por el delito de trata de personas, por nacionalidad y sexo. 
Tabla 4. Causas y víctimas del delito de trata de personas 2011 - 2019

\begin{tabular}{|c|c|c|}
\hline Años & Causas & Victimas \\
\hline 2011 & 10 & 92 \\
\hline 2012 & 1 & 7 \\
\hline 2013 & 4 & 80 \\
\hline 2014 & 5 & 9 \\
\hline 2015 & 4 & 7 \\
\hline 2016 & 6 & 13 \\
\hline 2017 & 3 & 10 \\
\hline 2018 & 5 & 16 \\
\hline 2019 & 6 & 37 \\
\hline Total & 44 & 267 \\
\hline
\end{tabular}

Fuente: Elaboración propia con datos de Mesa Intersectorial Trata de Personas, 2019, p. 9.

Tabla 5. Víctimas de trata de personas por año y tipo 2011-2019

\begin{tabular}{|c|c|c|}
\hline Año & Trata Laboral & Trata Sexual \\
\hline 2011 & 57 & 35 \\
\hline 2012 & - & 7 \\
\hline 2013 & 79 & 1 \\
\hline 2014 & 1 & 8 \\
\hline 2015 & 3 & 4 \\
\hline 2016 & 2 & 11 \\
\hline 2017 & 4 & 2 \\
\hline 2018 & 12 & 4 \\
\hline 2019 & 2 & 35 \\
\hline Totales & 160 & 107 \\
\hline
\end{tabular}

Fuente: Elaboración propia con datos de Mesa Intersectorial Trata de Personas, 2019, p. 10. 
Tabla 6. Condenados por el delito de trata de personas por nacionalidad y sexo $2011-2019$

\begin{tabular}{|c|c|c|}
\hline Nacionalidad & Femenino & Masculino \\
\hline Chilena & 5 & 4 \\
\hline Argentina & - & 1 \\
\hline Boliviana & 3 & 2 \\
\hline Dominicana & 2 & - \\
\hline Peruana & 1 & 1 \\
\hline Ecuatoriana & 4 & 4 \\
\hline Rusa & - & 1 \\
\hline India & - & 1 \\
\hline Colombiana & - & 1 \\
\hline Totales & 15 & 15 \\
\hline
\end{tabular}

Fuente: Elaboración propia con datos de Mesa Intersectorial Trata de Personas, 2019, p. 9.

La trata de personas, que somete a trabajos forzosos y explotación, laboral y sexual, a hombres y mujeres, es uno de los delitos más violentos contra los derechos humanos, pero al mismo tiempo, un negocio muy lucrativo para las actividades comerciales ilícitas del COT. Por estas razones, tanto a nivel internacional como nacional, esta actividad ilegal es perseguida criminalmente por las autoridades de los distintos gobiernos.

En el caso de Chile, desde 2011, año en que se dictó la ley № 20.507 que tipificó los delitos de tráfico ilícito de migrantes y trata de personas, el gobierno aplicó una serie de normas para su prevención e impuso varias medidas para su persecución criminal. Esta normativa permitió controlar estas actividades subterráneas, razón por la que el país calificó en el concierto internacional para el Nivel 1 (TIER 1), a partir de 2014. 
Un caso documentado en la Fiscalía describe la forma de operar de los traficantes, en el que se mezclan dos situaciones: se facilita el cruce de frontera y se ofrece un trabajo que resulta en trabajo forzoso o trata de explotación laboral. Declara la ciudadana peruana J.A.Q. al Fiscal Bobadilla lo siguiente: en diciembre (2011), cerca de su casa, se acercó un ciudadano peruano, A.T. que le prometió "un pago diario de US\$30 dólares, más traslados, alojamiento y alimentación" [para] trabajar en una cosecha de ciruelas. Luego, relata que en febrero, "(...) ella y sus otros 42 compatriotas, todos oriundos de Tacna, viajaron en bus hasta Arica, a través del paso fronterizo de Chacalluta", porque la oferta era muy conveniente. Con estos y otros antecedentes, el Fiscal acreditó que el empresario chileno, E.M. se coludió con el ciudadano peruano, A.T. que ofreció el trabajo y que ingresó a los peruanos en calidad de turistas. En el fondo, "Facilitó su entrada ilegal para obtener mano de obra barata para su predio, donde (los peruanos) estuvieron en condiciones deplorables, con hambre y frío". Finalmente, el empresario E.M. fue condenado a tres años de presidio remitido y a una multa de 72 UTM (\$2.800.000) por tráfico de migrantes" (Rodríguez; Labrín; Riquelme, 2013).

Pese a todos los controles establecidos, el aumento de los negocios ilegales relacionados con la trata de personas en el país ha sido notorio. La Brigada Investigadora de Trata de Personas (BITRAP) informó que el número de casos vinculados con este delito, en 2017, fue de 27 y que para 2019 alcanzó 376 y que los migrantes procedentes de Venezuela, República Dominicana y Cuba son los que llegan en mayor cantidad por pasos no habilitados. En su informe, la BITRAP señala que "(...) en noviembre del año pasado [2019] fue desarticulada una banda que se dedicaba a reclutar a mujeres colombianas para ejercer la prostitución a través de videos en los que se les ofrecía trabajos bien remunerados" (TRT, 2020)

Este delito, así como la trata de personas, experimentó un giro en Chile, en 2011, tras la promulgación de la Ley 20.507, que tipificó y diferenció estos ilícitos. Las organizaciones que los cometen también modificaron sus formas de operar.

En definitiva, la trata de personas implica explotación, coerción y violación de los derechos humanos; aspectos que no se asocian al tráfico ilícito de migrantes. 


\section{¿Qué es el tráfico ilícito de migrantes?}

En términos generales, es una forma de traficar seres humanos, pero de acuerdo al Protocolo contra el tráfico ilícito de migrantes por tierra, mar y aire se menciona que

Por "tráfico ilícito de migrantes" se entenderá la facilitación de la entrada ilegal de una persona en un Estado Parte del cual dicha persona no sea nacional o residente permanente con el fin de obtener, directa $o$ indirectamente, un beneficio financiero u otro beneficio de orden material (UN, 2000).

Luego, el mismo protocolo señala que la "entrada ilegal" se produce cuando se pasan las fronteras sin cumplir los trámites necesarios que permitan entrar legalmente en el país que recibe al migrante; y que un "documento de identidad o de viaje falso" es cualquier documento de viaje o de identidad" que sea:

Elaborado o expedido de forma espuria o alterado materialmente por cualquiera que no sea la persona o entidad legalmente autorizada para producir o expedir el documento de viaje o de identidad en nombre de un Estado; 0

Expedido u obtenido indebidamente mediante declaración falsa, corrupción o coacción o de cualquier otra forma ilegal; o Utilizado por una persona que no sea su titular legitimo (NU, 2000).

A nivel mundial, el crimen organizado realiza sus negocios de tráfico ilícito de migrantes mediante un modelo similar al de sus otros mercados transnacionales, que tienen como característica, estar impulsados “...por una demanda y una oferta de servicios de tráfico que busca eludir las regulaciones existentes" (Gobierno de España, 2018).

Según el informe citado, durante 2016, el tráfico ilícito de migrantes en todo el mundo comprometió los derechos humanos de, al menos, 2,5 millones de personas y generó ganancias por cerca de 7.000 millones de dólares para los traficantes. El informe señala, además, que los traficantes han desarrollado nuevos sistemas para eludir los controles fronterizos, ocupan rutas muy peligrosas y desinforman a los migrantes sobre las condiciones del viaje. El informe aporta otros datos y da como ejemplo que desde 2014 la llegada de migrantes irregulares y refugiados a Europa ha tenido un aumento significativo, a tal punto que Europol especifica que más del $90 \%$ 
de los migrantes irregulares utilizan los servicios de los traficantes en algún momento de su viaje. (Gobierno de España, 2018).

Otro aspecto interesante del informe se refiere a que los traficantes han formado redes delictivas y facilitadoras de las operaciones que permiten traficar con las personas. Estas redes “...han desarrollado esquemas complejos que incluyen matrimonios falsos, trabajos inexistentes, falsificación de documentos y, en muchos casos, cohecho de funcionarios, es decir, corrupción sistemática de las autoridades de los países parte de las rutas migratorias"(Gobierno de España, 2018).

La situación del tráfico ilícito de migrantes en América del Sur, a diferencia de Europa, presenta otros aspectos. La mayoría de los países alineados en el acuerdo MERCOSUR eliminaron los trámites de visado para los ciudadanos de los países miembros, por lo que no es necesario el contrabando de migrantes para la mayoría de los habitantes de la región. No obstante, el mayor número de los migrantes de contrabando dentro y a través de América del Sur “...parecen ser ciudadanos de países del Caribe. Algunos migrantes también son contrabandeados de otros continentes, en particular, África y Asia" (ONU.UNODOC, 2018, p. 101).

Para Chile, el problema también es importante y, pesar de que la ley № 20.507 entrega atribuciones de control al gobierno es difícil conocer cómo opera el modelo del tráfico de migrantes, quiénes lo ejecutan y qué ganancias se llevan los operadores. Sin embargo, con los operativos policiales, que han permitido desbaratar algunas de las redes de traficantes, sobre todo en el norte del país, en la frontera con Perú, y los datos proporcionados por las mismas víctimas se ha podido estimar datos generales de la actividad de contrabando de personas.

Las autoridades chilenas han señalado que ciudadanos de la República Dominicana llegan irregularmente a Chile. La ruta de los migrantes que tienen como destino Chile es manejada por los traficantes

(...) primero a Ecuador o Colombia, y desde allí, hacia las partes septentrionales de Chile por tierra a través del Estado Plurinacional de Bolivia o Perú. El número de deportaciones de ciudadanos dominicanos debido a la entrada clandestina aumentó significativamente, en Chile en 2015, pero sigue siendo relativamente bajo, de casi 600 (ONU.UNODOC, 2018, pp. 101-102). 
El coordinador de la Red Iberoamericana de Fiscales Especializados contra la Trata de Personas, fiscal Emiliano Arias, declara que:

(...) hemos visto un importante flujo de ciudadanos que son contactados en sus países por agencias o grupos criminales, que les prometen mejores condiciones laborales. Luego, empleando un contacto falso en Chile, les entregan una carta de invitación que acredita que están de paso Las bandas dedicadas al tráfico de migrantes, según la fiscalía, pueden ganar desde US\$1.000...hasta US\$ 3.000, por cada ilegal ingresado a Chile. (Rodríguez; Labrín; Riquelme, 2013).

El caso de los ciudadanos bolivianos de Cochabamba es un nuevo episodio de tráfico y trata simultáneamente. Un reporte de la Fiscalía Nacional muestra que, entre abril de 2011 y marzo de 2013, hubo 35 casos de tráfico de inmigrantes y 57 de trata de personas, 46 de los cuales tenían fines "sexuales" y 11 "laborales". Estos hechos han afectado, al menos, a 311 extranjeros (Rodríguez; Labrín; Riquelme, 2013). Entre estos últimos casos está el que la Fiscalía de la VII Región del Maule constató en 2012. La empresa P.E. Limitada reclutó un grupo de bolivianos procedentes de Cochabamba que fueron llevados en bus hasta lquique y luego trasladados a la VII Región, donde la policía constató que trabajaban de obreros y vivían en tres casas, con apenas dos baños. "Sólo me han cancelado una parte del sueldo de febrero, correspondiente a US $\$ 550$ y no los US $\$ 700$ ofrecidos. Los meses de marzo, abril y mayo aún me los deben. Sólo nos dan adelantos los sábados, de \$10 o \$20 mil para útiles de aseo", relató a la fiscalía M.C. "Nos gustaría seguir, acá ganamos entre \$250 mil y 700 mil, según la experiencia, bastante más que el sueldo mínimo chileno" (Rodríguez, Labrín, Díaz y Riquelme, 2013), apuntó C.R.

En el norte de Chile, la Fiscalía Nacional investigó un grupo de migrantes dominicanos que cruzaron ilegalmente la frontera de Chile con Perú.

De acuerdo a las primeras diligencias, el hecho se registró cerca de las 5 de la madrugada de este domingo [22 de mayo 2016] cuando D.S, de 24 años, se desplazaba por territorio chileno, por el sector de quebrada escritos, cuando activó una mina antipersonal resultando gravemente lesionado en su pie izquierdo.

A raíz del accidente, otros cuatros ciudadanos dominicanos que lo acompañaban (tres hombres y una mujer) lo cargaron trasladándose hasta la zona de la carretera donde fueron auxiliados por funcionarios de carabineros de la Cuarta Comisaría de Chacalluta, quienes 
trasladaron al afectado hasta la unidad de emergencia del Hospital Doctor Juan Noé (Fiscalía Nacional (FN), 2016).

Según se estableció en el juicio por el Tribunal Oral en lo Penal de Arica, el delito cometido por los traficantes afectaba al grupo de dominicanos que cruzó la frontera el 22 de mayo de 2016 y que correspondía a uno de los tantos grupos que contrataban a agencias de tráfico de migrantes para ciudadanos de ese país. Según se estableció en el juicio, la agencia captaba dominicanos en su país y les ofrecía traslado hacia Chile, bajo el engaño de entregarles visas de trabajo. Por esta diligencia ilícita los traficantes cobraban sumas entre los 700 a los 3 mil dólares. Una vez concertado el viaje, los migrantes eran trasladados por vía aérea hasta Colombia o Ecuador, para seguir su camino por vía terrestre, en buses, camionetas o automóviles, hacia Perú. En este último país, la red tenía habilitadas casas de acopio de personas en Sullana, junto a la frontera con Ecuador, y también en Tacna (DavidNoticias, 2018).

Las actividades de tráfico ilícito de migrantes citadas, naturalmente impactan por la cruda realidad que presentan, no obstante, no se comparan con la más grande que ha existido en la historia de nuestro país, según palabras de la subsecretaria de Prevención del Delito, Katherine Martorell (EMOL, 2019). La organización que llevaba adelante estos negocios ilícitos la integraban once personas, entre las cuales había tres ex autoridades públicas, formalizadas por su presunta participación en la creación de una red de trata de personas que introdujo a Chile un total de 381 ciudadanos chinos mediante cartas de invitación falsas (El Mostrador, 2019) Durante 6 meses la Policía de Investigaciones (PDI) investigó el negocio de la Organización Gestiones Integrales SPA que se encargaba de extender cartas de invitación, ideológicamente falsas, con las que los ciudadanos chinos que pagaban US $\$ 5.000$, por persona, podían obtener una visa de turismo para ingresar a Chile. La organización fue imputada por la Fiscalía por el ingreso ilegal de 381 ciudadanos chinos (24 Horas, 2019), de los cuales, 110 tienen visa de residencia, 33 están tramitando su visa y 60 están en situación de migrante irregular, sin paradero conocido. Además, 178 de ellos pasaron a la República Argentina (EMOL, 2019).

En la condición de sociedad receptora y bajo el prisma de la nueva inmigración, caracterizada por el flujo migratorio regional y transfronterizo, el país ha recibido un importante número de migrantes en los últimos años. Junto con estos migrantes regulares, el país ha recibido un número 
importante de migrantes en condición de trata de personas o de tráfico de migrantes. Aunque los controles establecidos por la ley № 20.507 han permitido desbaratar muchos de estos negocios ilegales, siempre van seguir existiendo por el bajo riesgo, escasa visibilidad que presentan y las altas ganancias que reportan estos crímenes y delitos contra los derechos de las personas.

\section{Conclusión}

La circulación de personas a través de las fronteras de Chile, con Argentina, Bolivia, y Perú ha aumentado en el marco de los movimientos migratorios regulares y legales, principalmente provenientes de Colombia, Venezuela, Ecuador, aunque también se observa la presencia de personas de República Dominicana, de Haití, y otros países como Siria o países de África y de Medio Oriente. Sin embargo, junto a estas migraciones regulares, se presentan migraciones irregulares, ilegales, provenientes del tráfico de migrantes y de la trata de personas que complican el cruce de fronteras de los migrantes que han elegido a la sociedad chilena como sociedad de acogida.

En estos últimos años, Chile se convirtió en país de destino de migrantes transfronterizos y regionales, razón por la que es necesario que adopte políticas migratorias equilibradas, que establezcan una legislación moderna en sus principios, flexible en sus categorías migratorias, funcional en cuanto a lo social y diversa para facilitar espacios de multiculturalidad. Con este tipo de legislación el país podrá enfrentar con mejores herramientas legales el problema de la migración irregular, la trata de personas y el tráfico de migrantes, con lo cual conseguirá que la migración sea segura, ordenada y regular.

\section{Bibliografía}

Araya Castelli, D.; Cifras Céspedes, L. y Oliveri Gutiérrez, A. (2007). Trata de niños/as y adolescentes: Una realidad oculta. OIM - ONG Raíces. Recuperado de: https://www.ongraices.org/admin/doctos/doc_14.pdf

Beck, U. (1998). ¿Qué es la globalización? Falacias del globalismo, respuestas a la globalización. Paidós. 
Bravo, G. (2015). Las migraciones internacionales y la seguridad multidimensional en tiempos de la globalización. Revista Diálogo Andino, (48), 139-149.

Bravo, G. y Norambuena, C. (2018). Procesos migratorios en Chile. Una mirada histórica normativa. Anepe.

Castells, M. (2005).Globalización, desarrollo y democracia: Chile en el contexto mundial. Fondo de Cultura Económica.

Channing, M. (2017). Transnational Crime and the Developing World. Global Financial Integrity. Transnational Crime and the Developing World. Recuperado de: https://gfintegrity.org/report/transnational-crime-andthe-developing-world/

DavidNoticias (2018). Tribunal de Arica condena a cuatro personas culpables de la mayor red de tráfico de migrantes descubierta en Chile. Recuperado de http://www.davidnoticias.cl/2018/10/31/tribunalarica-condena-cuatro-personas-culpables-la-mayor-red-traficomigrantes-descubierta-chile/

Dehesa, G. (2000). Comprender la globalización. Ed. Alianza.

Della Penna, C. (2014). La globalización como factor propiciador de la criminalidad organizada transnacional y la trata de personas. Revista ESD. Estudio s de Seguridad y Defensa, (4), 45-120.

EMOL (2019). PDI detalla funcionamiento de tráfico de migrantes: Les cobraban y entregaban cartas falsas de invitación. Recuperado de: https://www.emol.com/noticias/Nacional/2019/05/25/949068/Policiade-Investigaciones-entrega-detalles-del-funcionamiento-del-red-detrata-de-personas-que-opero-en-Chile.html

El Mostrador (2019). Tráfico de migrantes: PDI detecta envío de más de USD 1 millón desde China a Chile. Recuperado de: https://www.elmostrador.cl/noticias/pais/2019/06/06/trafico-demigrantes-pdi-detecta-envio-de-mas-de-usd-1-millon-desde-china-achile/

Fiscalía Nacional. Fiscalía de Arica (2016). Fiscalía investiga incidente en que extranjero resultó herido por mina antipersonal en la frontera. Recuperado de https://www.fiscaliadechile.cl/actualidad/noticias/regionales/aricafiscalia-investiga-incidente-en-que-extranjero-resulto-herido 
Gobierno de España. Departamento de Seguridad Nacional. (2018). Informe global de tráfico de migrantes 2018. Recuperado de: https://www.dsn.gob.es/es/actualidad/sala-prensa/informe-globaltrafico-migrantes-2018

Gobierno de Estados Unidos. Departamento de Estado (2016). Trafficking in Persons Report 2016. Recuperado de https://20092017.state.gov/documents/organization/258876.pdf

Gobierno de Estados Unidos. Departamento de Estado (2018). Trafficking in Persons Report 2018. Recuperado de https://www.state.gov/wpcontent/uploads/2019/01/282798.pdf

Instituto Nacional de Estadísticas (INE) (1982-2012). Censos de Población $1982 y \quad 2012 . \quad$ Recuperado de: http://historico.ine.cl/canales/chile_estadistico/censos/censo_ poblacion_vivienda.php

Itzingsohn, J. (2003). Migración, globalización y geopolítica. Anuario Social y Político de América Latina y El Caribe, (6), 72-82.

Rodríguez, S.; Labrín, S., Díaz, F. y Riquelme, P. (2013).Las rutas y el funcionamiento del tráfico de inmigrantes en Chile. La Tercera. 1 de junio. Recuperado de: https://www.latercera.com/noticia/las-rutas-y-elfuncionamiento-del-trafico-de-inmigrantes-en-chile/

Lucas. J. de. (2004). La inmigración, como res política. En J. Chamizo y Yamgnane, K. (Coords.). Movimientos de personas e ideas y multiculturalidad. Vol. II (pp. 193-225) Universidad de Deusto.

Ministerio de Interior. Mesa Intersectorial Trata de Personas (2019). Informe estadístico sobre Trata de Personas en Chile 2011-2019. Recuperado de: $\quad$ http://tratadepersonas.subinterior.gov.cl/noticias/informeestadistico-sobre-trata-de-personas-en-chile-2011-2019/

Naciones Unidas (2000). Protocolo contra el tráfico ilícito de migrantes por tierra, $\operatorname{mar} y$ aire. Recuperado de: http://www.oas.org/juridico/spanish/tratados/sp_proto_cont_tráfi_l\%C3 \%ADci_migra_tierra_mar_aire_comple_conve_nu_cont_delin_orga_tr ansn.pdf

Naciones Unidas (2012). Chile. Migrantes. 18 de enero. Recuperado de http://www.onu.cl/es/sample-page/agencias-fondos-y-programas/oim/ 
Organización de Estados Americanos. (OEA). (2003). Conferencia Especial sobre Seguridad. Declaración sobre seguridad en las Américas. Recuperado de http://www.oas.org/36AG/espanol/doc_referencia/DeclaracionMexico_ Seguridad.pdf

Organización Internacional para las Migraciones (OIM) (2006). Derecho Internacional sobre Migración. Glosario sobre Migración №7. Recuperado de: https://publications.iom.int/system/files/pdf/iml_7_sp.pdf

ONU. UNODOC (2004). Convención de las Naciones Unidas contra la delincuencia organizada transnacional y sus protocolos, 44-45. Recuperado de: https://www.unodc.org/documents/treaties/UNTOC/Publications/TOC \%20Convention/TOCebook-s.pdf

ONU. UNODOC. (2018). Global Study on Smuggling of Migrants 2018. Nueva York. Recuperado de https://www.unodc.org/documents/dataand-analysis/glosom/GLOSOM_2018_web_small.pdf

ONU. UNODOC (s/f). La trata de personas: Una compraventa de seres humanos. Recuperado de: https://www.unodc.org/toc/es/crimes/human-trafficking.html

Trigo Portela, J. Tremosa I Balcells, R. y Viñeta, S. (2003). L'empresa catalana en l'economia global. Papers d'economia industrial, (19). Recuperado de: https//mpresa.gencat.cat/web/.content/001departament/04-serveis/01-

publicacions/Empresa_Industria/papers_d_economia_industrial/docu ments/arxius/doc_32020597_1.pdf

TRT (2020). Trata de personas en Chile aumentó un 1.300\% en los últimos tres años. Recuperado de: https://www.trt.net.tr/espanol/vida-ysalud/2020/02/18/trata-de-personas-en-chile-aumento-un-1-300-enlos-ultimos-tres-anos-1361508

United Nations (2017). International Migration Report 2017. Recuperado de: http://www.un.org/en/development/desa/population/migration/publi cations/migrationreport/docs/MigrationReport2017_Highlights.pdf 
24 Horas (2019). Así operaba la mayor red de tráfico de migrantes en la historia de Chile. Recuperado de: https://www.24horas.cl/nacional/asioperaba-la-mayor-red-de-trafico-de-migrantes-en-la-historia-de-chile3338793

Zolo, D. (2000). Cosmópolis. Perspectiva y riesgos de un gobierno mundial. Ed. Paidos. 